\title{
Using Correction Equations Based on Measured Height and Weight Weakens Associations between Obesity Based on Self-Reports and Chronic Diseases
}

\author{
Cynthia L. Murray, ${ }^{1}$ Gordon W. Walsh, ${ }^{2}$ and Sarah Connor Gorber ${ }^{3}$ \\ ${ }^{1}$ School of Nursing, Memorial University, St. John's, NL, Canada A1B 3 V6 \\ ${ }^{2}$ Surveillance and Epidemiology Unit, Cancer Care Nova Scotia, Halifax, NS, Canada B3H 2 Y9 \\ ${ }^{3}$ Center for Chronic Disease Prevention and Control, Public Health Agency of Canada, Ottawa, ON, Canada K1A OK9 \\ Correspondence should be addressed to Cynthia L. Murray; cindym@mun.ca
}

Received 10 November 2012; Revised 26 December 2012; Accepted 28 December 2012

Academic Editor: Michael Leitzmann

Copyright (c) 2013 Cynthia L. Murray et al. This is an open access article distributed under the Creative Commons Attribution License, which permits unrestricted use, distribution, and reproduction in any medium, provided the original work is properly cited.

\begin{abstract}
Objective. Researchers have established a preponderance of height overestimation among men and weight underestimation among women in self-reported anthropometric data, which skews obesity prevalence data and obscures obesity-chronic disease relationships. The objective of this study was to reevaluate associations between obesity and chronic diseases using body mass index (BMI) correction equations derived from measured data. Methods. Measured height and weight (MHW) data were collected on a subsample of the 17,126 Atlantic Canadians who participated in the 2007-2008 Canadian Community Health Survey (CCHS). To obtain corrected BMI estimates for the 17,126 adults, correction equations were developed in the MHW subsample and multiple regression procedures were used to model BMI. To test obesity-chronic disease relationships, logistic regression models were utilized. Results. The correction procedure eliminated statistically significant relations $(P<0.05)$ between obesity and chronic bronchitis and obesity and stroke. Also, correction attenuated many relationships between adiposity and chronic disease. For example, among obese adults, there was a $13 \%, 12 \%$, and $7 \%$ reduction in the adjusted odds ratios for asthma, urinary incontinence, and cardiovascular disease, respectively. Conclusion. Further research is needed to fully understand how the usage of self-reported data alters our understanding of the relationships between overweight or obesity and chronic diseases.
\end{abstract}

\section{Introduction}

With over one billion people overweight (body mass index (BMI) $25.0-29.9 \mathrm{~kg} / \mathrm{m}^{2}$ ) and 500 million obese (BMI $\geq$ $30.0 \mathrm{~kg} / \mathrm{m}^{2}$ ), the World Health Organization (WHO) considers obesity to be a global epidemic $[1,2]$. Obesity is listed as a risk factor for cardiovascular disease (CVD, that is, hypertension, stroke, congestive heart failure, and coronary artery disease), type 2 diabetes, several types of cancer (i.e., colorectal, kidney, breast, endometrial, ovarian, and pancreatic), asthma, gallbladder disease, osteoarthritis, and chronic back pain [3]. Besides the heavy toll on morbidity and mortality rates exacted especially by severe obesity $[4,5]$, excess body fat also reportedly has a substantial economic burden on society. In Canada, the direct medical cost of overweight and obesity was $\$ 6.0$ billion in 2006 [6].

While research has shown that obesity is associated with a number of chronic health conditions [1, 7], the relationships, though still significant, may be weaker than once thought [8-12]. Most studies investigating the link between obesity and adverse health outcomes use self-reported height and weight data, which can be distorted by bias and error [8], to determine BMI. Canadian researchers demonstrated, with correction equations based on measured data, that the outcome of using self-reported data is an underestimation of obesity prevalence, but an overestimation of the association between obesity and chronic disease [8]. It is fundamental to reevaluate the relationship between obesity and chronic 
health conditions because the results inform the work of health care practitioners, researchers, planners, and decision makers.

Despite the limitations faced in using self-reported height and weight data, the practice will likely continue in large national surveys due to fiscal and logistical constraints [13]. The Canadian Community Health Survey (CCHS) is unconventional in that it includes both self-reported and direct measurements of height and weight from $10 \%$ of the respondents. By analysing CCHS data, researchers have a unique opportunity to take a better look at the link between obesity and chronic diseases. The purpose of this study was to examine the relationship between obesity and chronic diseases by conducting a secondary data analysis of 20072008 CCHS data in the Atlantic region of Canada, which has the highest obesity prevalence rates in the country [7].

This secondary data analysis of the 2007-2008 CCHS was performed to answer the following research question: what are the relationships between selected chronic health conditions (e.g., type 2 diabetes, CVD, and cancer) and obesity in Atlantic Canada using (a) self-reported BMI estimates, and (b) corrected BMI estimates based on measured data? The research was approved by Statistics Canada, the Social Sciences and Humanities Research Council of Canada (SSHRC), and the Interdisciplinary Committee on Ethics in Human Research (ICEHR) at Memorial University in St. John's, Newfoundland and Labrador.

\section{Methods}

The CCHS is a national representative survey, which collects self-reported information on health status, health care utilization, and health determinants for the Canadian population [14]. In the section of the CCHS on chronic health conditions, respondents are asked if they have certain chronic health conditions for a duration of 6 months or more that have been diagnosed by a health professional $[14,15]$. A full description of the 2007-2008 CCHS is available from Statistics Canada publications $[14,15]$. Briefly, the target population of the 2007-2008 CCHS was persons aged 12 years and over living in private dwellings in all provinces and territories. The survey excludes persons living on Aboriginal reserves and settlements or in institutions, full-time members of the Canadian Forces, and residents of certain remote regions. For the Atlantic region, the response rates were $82 \%, 79 \%, 80 \%$, and $82 \%$ for the provinces of Newfoundland and Labrador, Prince Edward Island, Nova Scotia, and New Brunswick, respectively, yielding a total of 17,126 Atlantic Canadian respondents. The CCHS 2007-2008 cycle had three sampling frames to select the sample of households as follows: $49 \%$ of the sample of households came from an area frame, $50 \%$ were from a list frame of telephone numbers, and $1 \%$ came from a random digit dialing sampling frame. The secondary analysis included all 2007-2008 CCHS Atlantic Canadian respondents, with the exception of pregnant and breastfeeding women and children under the age of 18 because the BMI is not intended for use with these groups [16]. The sociodemographic characteristics of the Atlantic Canadian population are described elsewhere [17].
In 2008, measured height and weight (MHW) data were collected on a subsample of the CCHS respondents. These measured data were used to generate correction equations for males and females to adjust self-reported BMI estimates in Atlantic Canada [17] according to previously validated methods [8]. Details of the correction equations and the analyses indicating there was sufficient statistical power are published elsewhere [17]. This research is based on and extends a previous analysis that examined the relationships between obesity and a smaller set of chronic diseases at the national level [10].

2.1. Statistical Analyses. A preliminary analytical step was assessing the prevalence of "obesity-related" chronic health conditions in the Atlantic provinces versus Canada overall. Next, we applied the correction equations developed in the MHW subsample [17] to the self-reported obesity data from the CCHS. The extent to which self-reported measures of height and weight (BMI) bias the relationship between obesity and select obesity-related chronic conditions was then determined, using logistic regression models with selfreported and corrected BMI as independent variables and the presence of each chronic condition (yes/no) serving as the dependent variable. We used a derived variable, namely CVD, which included the presence of heart disease, high blood pressure, and/or diabetes. Age and sex were controlled for in the models. The analyses were restricted to men and women aged 40 and older due to the higher prevalence of chronic disease among this age group.

The researchers adhered to Statistics Canada's guidelines for tabulation, analysis, and release $[14,15]$. The data analysis was conducted at the Atlantic Research Data Centre (ARDC) at Dalhousie University in Halifax, Nova Scotia, using SAS 9.2 statistical software (SAS Institute Inc., Cary, NC).

\section{Results}

Information on the prevalence of obesity-related chronic health conditions among adults aged 40 years or older in Atlantic Canada as compared to the rest of Canada appears in Table 1. The percentage of Atlantic Canadian adults in this age group who reported having been given a medical diagnosis of anxiety disorder, arthritis, CVD, diabetes, heart disease, and/or high blood pressure was significantly higher $(P<0.0001)$ than among those living in the provinces and territories outside of the Atlantic region. Just over 30\% of the Atlantic Canadian adults aged 40 years and older had arthritis and/or high blood pressure, and slightly under $40 \%$ had CVD. In contrast, closer to one-quarter had arthritis (24\%) and/or high blood pressure (27\%), and $34 \%$ of nonAtlantic Canadians had CVD.

The results of the logistic regression analyses are displayed in Table 2. In two cases, the relationship between a chronic condition and obesity lost statistical significance with the correction for bias and error. In particular, on self-report, obesity was significantly associated with stroke and chronic bronchitis at the .05 level, but upon correction these results were no longer significant. Also, correction attenuated many 
relationships between adiposity and chronic disease. For example, among obese adults, there was a $13 \%, 12 \%$, and $7 \%$ reduction in the adjusted odds ratios (AOR) for asthma (precorrection $\mathrm{AOR}=1.88 ; 95 \%$ confidence interval $(\mathrm{CI})$ 1.40-2.53; postcorrection $\mathrm{AOR}=1.64 ; 95 \%$ CI 1.19-2.26), urinary incontinence (precorrection AOR $=1.74 ; 95 \% \mathrm{CI}$ 1.34-2.26; postcorrection $\mathrm{AOR}=1.54 ; 95 \% \mathrm{CI} 1.17-2.02$ ), and CVD (precorrection $\mathrm{AOR}=4.86 ; 95 \% \mathrm{CI} 4.18-5.64$; postcorrection AOR $=4.52$; 95\% CI 3.84-5.32), respectively. For those who were overweight, correction for bias and error decreased, for instance, the AORs for CVD (precorrection $\mathrm{AOR}=1.99 ; 95 \%$ CI 1.74-2.29; postcorrection $\mathrm{AOR}=1.80$; 95\% CI 1.54-2.10) and high blood pressure (precorrection $\mathrm{AOR}=1.97 ; 95 \%$ CI 1.70-2.27; postcorrection $\mathrm{AOR}=1.85$; $95 \%$ CI $1.57-2.18$ ) by $10 \%$ and $6 \%$, respectively.

All of the relationships tested between chronic disease/condition and BMI, specifically when BMI was analyzed as a continuous variable, were basically unaltered by the correction process. Other than cancer, the chronic health conditions were positively associated with increasing body weight. Furthermore, with the exception of asthma, chronic bronchitis, and pain/discomfort, underweight was significantly associated pre- and/or postcorrection with the chronic health conditions under investigation. Two irregular findings were observed in Table 2, in that there was a significant relationship after, but not before, correction between underweight and arthritis (AOR $=1.31 ; 95 \%$ CI 1.02-1.69; $P<$ 0.05 ) and overweight and pain and discomfort ( $\mathrm{AOR}=1.34$; 95\% CI 1.08-1.66; $P<0.01)$. Nevertheless, it was noted that the point estimates approached significance on self-report for overweight adults for pain and discomfort $(P=0.07)$ and for underweight adults for arthritis $(P=0.06)$.

\section{Discussion}

Ever since the 1970s, federal government health reports, such as the Lalonde Report [18] in Canada and the 1979 Surgeon General's Report [19] in the United States, have cautioned the public at large about the dangers of lack of physical exercise and a high-caloric or high-fat diet. One problem with many studies examining the link between obesity and adverse health outcomes is the use of self-reported BMI data, which can be distorted by bias and error [8]. The current study capitalizes on the recent advent of correction equations in order to reassess the obesity-chronic disease relationship.

In this large study, we found a high prevalence of chronic diseases in the Atlantic provinces of Canada, notwithstanding the restriction of the analysis to individuals 40 years of age or older. Arthritis and cardiovascular-related diseases, such as high blood pressure, were particularly prevalent in this geographical region of the country. This finding was not entirely unexpected as there is ample empirical evidence $[20,21]$ to support the idea of the Atlantic area being an epicenter of chronic diseases in Canada. Yet, we cannot directly compare our results with other publications because we limited our analysis to an older age group. The PHAC [21], for instance, provided statistics on CVD for Canadians who were 20 years of age and older. In this younger population,
TABLE 1: Prevalence of obesity-related chronic health conditions by Canadian region, household population aged 40 years or older, 2007-2008.

\begin{tabular}{lcccc}
\hline \multirow{2}{*}{ Chronic condition } & \multicolumn{2}{c}{ Atlantic Canada } & \multicolumn{2}{c}{ Rest of Canada } \\
& $\%$ & $95 \%$ CI & $\%$ & $95 \%$ CI \\
\hline Anxiety disorder & $6.7^{*}$ & $6.0,7.3$ & 5.4 & $5.1,5.7$ \\
Arthritis & $31.6^{*}$ & $30.4,32.7$ & 24.3 & $23.8,24.8$ \\
Asthma & 7.3 & $6.6,8.0$ & 7.4 & $7.1,7.7$ \\
Cancer & 3.2 & $2.8,3.7$ & 3.1 & $2.9,3.3$ \\
Cardiovascular disease & $38.6^{*}$ & $37.3,39.8$ & 33.7 & $33.1,34.3$ \\
Chronic bronchitis & 1.9 & $1.6,2.2$ & 1.8 & $1.6,1.9$ \\
Depression & 7.8 & $7.1,8.5$ & 7.4 & $7.1,7.7$ \\
Diabetes & $11.8^{*}$ & $11.1,12.6$ & 9.4 & $9.1,9.8$ \\
Heart disease & $10.0^{*}$ & $9.3,10.7$ & 8.0 & $7.7,8.3$ \\
High blood pressure & $31.1^{*}$ & $29.9,32.3$ & 26.6 & $26.0,27.1$ \\
Pain and Discomfort & 11.9 & $11.1,12.6$ & 12.2 & $11.8,12.6$ \\
Stroke & 2.0 & $1.7,2.3$ & 1.8 & $1.7,2.0$ \\
Urinary incontinence & 5.5 & $5.0,6.0$ & 5.1 & $4.9,5.4$ \\
\hline
\end{tabular}

Data source: 2007-2008 Canadian Community Health Survey, Statistics Canada.

Abbreviations: CI: confidence intervals.

${ }^{*} P<0.0001$.

the percentage of adults who had high blood pressure ranged from $22 \%$ to $25 \%$ in the Atlantic provinces and ranged from $8 \%$ to $21 \%$ in the remaining provinces and territories, with a $19 \%$ national average [21]. We witnessed a markedly higher prevalence of high blood pressure for Atlantic (31\%) and other Canadians (27\%), but this may be attributed to the disparate age groups.

The results revealed that many significant relationships remained unchanged and robust despite the correction for bias and error. Increasing body weight, as indicated in Table 2 by the continuous BMI variable, was strongly associated preand postcorrection with anxiety disorder, arthritis, asthma, CVD, chronic bronchitis, depression, diabetes, heart disease, high blood pressure, pain and discomfort, stroke, and urinary incontinence. To our knowledge, this study is the first to make these pre- and postcorrection comparisons when BMI is treated as a continuous variable. However, these findings are consistent with research comparing measured versus uncorrected self-reported BMI data in regression models analyzing the correlations between BMI as a continuous variable and selected health conditions, including diabetes, high blood pressure, heart disease, and arthritis [10]. Being underweight was associated pre- and postcorrection with anxiety disorder, cancer, CVD, depression, diabetes, heart disease, high blood pressure, stroke, and urinary incontinence. These results are consistent with reports in the research literature that being underweight is a major chronic disease risk factor, especially in developing nations [22]. The finding that these relationships held postcorrection was expected because the difference between self-reported BMI and physical measurements is smallest among those with lower body weight [12].

The data analyses also exhibited statistically strong relationships between obesity and diabetes, CVD, high blood pressure, asthma, urinary incontinence, and arthritis, but 
TABLE 2: Adjusted odds ratios ${ }^{\mathrm{a}}$ relating corrected and self-reported BMI to selected health conditions, household population aged 40 years or older, Atlantic Canada, 2007-2008.

\begin{tabular}{|c|c|c|c|c|}
\hline \multirow{2}{*}{ BMI category (range $\mathrm{kg} / \mathrm{m}^{2}$ ) } & \multicolumn{2}{|c|}{ Based on self-reported BMI } & \multicolumn{2}{|c|}{ Based on corrected BMI } \\
\hline & Adjusted OR & $95 \% \mathrm{CI}$ & Adjusted OR & $95 \% \mathrm{CI}$ \\
\hline \multicolumn{5}{|l|}{ Anxiety disorder } \\
\hline Underweight $(<18.5)$ & $1.83^{\dagger}$ & $1.25,2.68$ & $1.90^{\dagger}$ & $1.27,2.84$ \\
\hline Normal weight (18.5 to 24.9 ; ref) & 1.00 & - & 1.00 & - \\
\hline Overweight (25.0 to 29.9 ) & 1.12 & $0.88,1.41$ & 0.99 & $0.76,1.28$ \\
\hline Obese ( 30.0 or more) & $1.47^{\dagger}$ & $1.14,1.90$ & $1.51^{\dagger}$ & $1.15,1.98$ \\
\hline BMI (continuous) & $1.03^{\ddagger}$ & $1.01,1.05$ & $1.03^{\ddagger}$ & $1.01,1.05$ \\
\hline \multicolumn{5}{|l|}{ Arthritis } \\
\hline Underweight $(<18.5)$ & 1.24 & $0.99,1.57$ & $1.31^{*}$ & $1.02,1.69$ \\
\hline Normal weight (18.5 to 24.9 ; ref) & 1.00 & - & 1.00 & - \\
\hline Overweight (25.0 to 29.9 ) & 1.16 & $1.00,1.34$ & 1.11 & $0.94,1.31$ \\
\hline Obese (30.0 or more) & $1.92^{\mathrm{x}}$ & $1.64,2.24$ & $1.81^{\mathrm{x}}$ & $1.53,2.15$ \\
\hline BMI (continuous) & $1.06^{\mathrm{x}}$ & $1.04,1.07$ & $1.05^{\mathrm{x}}$ & $1.04,1.07$ \\
\hline \multicolumn{5}{|l|}{ Asthma } \\
\hline Underweight $(<18.5)$ & 1.17 & $0.77,1.79$ & 1.11 & $0.70,1.76$ \\
\hline Normal weight (18.5 to 24.9 ; ref) & 1.00 & - & 1.00 & - \\
\hline Overweight (25.0 to 29.9 ) & 1.13 & $0.86,1.48$ & 0.95 & $0.69,1.31$ \\
\hline Obese ( 30.0 or more) & $1.88^{\mathrm{x}}$ & $1.40,2.53$ & $1.64^{\dagger}$ & $1.19,2.26$ \\
\hline BMI (continuous) & $1.05^{\mathrm{x}}$ & $1.03,1.06$ & $1.04^{\mathrm{x}}$ & $1.03,1.06$ \\
\hline \multicolumn{5}{|l|}{ Cancer } \\
\hline Underweight $(<18.5)$ & $1.61^{*}$ & $1.03,2.53$ & $1.60^{*}$ & $0.99,2.57$ \\
\hline Normal weight (18.5 to 24.9 ; ref) & 1.00 & - & 1.00 & - \\
\hline Overweight (25.0 to 29.9 ) & 1.19 & $0.86,1.64$ & 1.10 & $0.77,1.59$ \\
\hline Obese ( 30.0 or more) & 1.29 & $0.89,1.88$ & 1.20 & $0.81,1.78$ \\
\hline BMI (continuous) & 1.02 & $1.00,1.05$ & 1.02 & $1.00,1.05$ \\
\hline \multicolumn{5}{|l|}{ Cardiovascular disease } \\
\hline Underweight $(<18.5)$ & $2.03^{\mathrm{x}}$ & $1.58,2.60$ & $2.26^{\mathrm{x}}$ & $1.73,2.95$ \\
\hline Normal weight (18.5 to 24.9 ; ref) & 1.00 & - & 1.00 & - \\
\hline Overweight (25.0 to 29.9 ) & $1.99^{\mathrm{x}}$ & $1.74,2.29$ & $1.80^{\mathrm{x}}$ & $1.54,2.10$ \\
\hline Obese ( 30.0 or more) & $4.86^{\mathrm{x}}$ & $4.18,5.64$ & $4.52^{\mathrm{x}}$ & $3.84,5.32$ \\
\hline BMI (continuous) & $1.14^{\mathrm{x}}$ & $1.12,1.15$ & $1.13^{\mathrm{x}}$ & $1.12,1.15$ \\
\hline \multicolumn{5}{|l|}{ Chronic bronchitis } \\
\hline Underweight $(<18.5)$ & 1.17 & $0.61,2.25$ & 1.12 & $0.57,2.20$ \\
\hline Normal weight (18.5 to 24.9 ; ref) & 1.00 & - & 1.00 & - \\
\hline Overweight (25.0 to 29.9 ) & 0.99 & $0.61,1.63$ & 0.92 & $0.57,1.51$ \\
\hline Obese (30.0 or more) & $1.69^{*}$ & $1.10,2.61$ & 1.58 & $0.96,2.60$ \\
\hline BMI (continuous) & $1.04^{\dagger}$ & $1.01,1.07$ & $1.04^{\dagger}$ & $1.01,1.07$ \\
\hline \multicolumn{5}{|l|}{ Depression } \\
\hline Underweight $(<18.5)$ & $2.02^{\mathrm{x}}$ & $1.42,2.88$ & $2.16^{\mathrm{x}}$ & $1.46,3.20$ \\
\hline Normal weight ( 18.5 to 24.9 ; ref) & 1.00 & - & 1.00 & - \\
\hline Overweight (25.0 to 29.9 ) & 1.01 & $0.80,1.28$ & 1.06 & $0.81,1.37$ \\
\hline Obese ( 30.0 or more) & $1.47^{\dagger}$ & $1.15,1.89$ & $1.51^{\dagger}$ & $1.15,1.97$ \\
\hline BMI (continuous) & $1.03^{\mathrm{x}}$ & $1.02,1.05$ & $1.03^{\mathrm{x}}$ & $1.02,1.05$ \\
\hline \multicolumn{5}{|l|}{ Diabetes } \\
\hline Underweight $(<18.5)$ & $2.17^{\mathrm{x}}$ & $1.62,2.92$ & $2.60^{\mathrm{x}}$ & $1.89,3.57$ \\
\hline Normal weight (18.5 to 24.9 ; ref) & 1.00 & - & 1.00 & - \\
\hline Overweight (25.0 to 29.9 ) & $2.14^{\mathrm{x}}$ & $1.72,2.66$ & $2.07^{\mathrm{x}}$ & $1.63,2.63$ \\
\hline Obese (30.0 or more) & $6.39^{\mathrm{x}}$ & $5.22,7.83$ & $6.14^{\mathrm{x}}$ & $4.91,7.68$ \\
\hline BMI (continuous) & $1.15^{\mathrm{x}}$ & $1.13,1.17$ & $1.14^{\mathrm{x}}$ & $1.12,1.16$ \\
\hline
\end{tabular}


TABLE 2: Continued.

\begin{tabular}{|c|c|c|c|c|}
\hline \multirow{2}{*}{ BMI category (range $\mathrm{kg} / \mathrm{m}^{2}$ ) } & \multicolumn{2}{|c|}{ Based on self-reported BMI } & \multicolumn{2}{|c|}{ Based on corrected BMI } \\
\hline & Adjusted OR & $95 \% \mathrm{CI}$ & Adjusted OR & $95 \% \mathrm{CI}$ \\
\hline \multicolumn{5}{|l|}{ Heart disease } \\
\hline Underweight $(<18.5)$ & $1.54^{\dagger}$ & $1.11,2.15$ & $1.71^{\dagger}$ & $1.20,2.42$ \\
\hline Normal weight ( 18.5 to 24.9 ; ref) & 1.00 & - & 1.00 & - \\
\hline Overweight (25.0 to 29.9 ) & 1.19 & $0.97,1.47$ & 1.25 & $1.00,1.57$ \\
\hline Obese (30.0 or more) & $1.92^{\mathrm{x}}$ & $1.55,2.39$ & $1.96^{\mathrm{x}}$ & $1.58,2.43$ \\
\hline BMI (continuous) & $1.06^{\mathrm{x}}$ & $1.04,1.07$ & $1.06^{\mathrm{x}}$ & $1.04,1.07$ \\
\hline \multicolumn{5}{|l|}{ High blood pressure } \\
\hline Underweight $(<18.5)$ & $1.88^{\mathrm{x}}$ & $1.49,2.38$ & $2.12^{\mathrm{x}}$ & $1.65,2.72$ \\
\hline Normal weight (18.5 to 24.9 ; ref) & 1.00 & - & 1.00 & - \\
\hline Overweight (25.0 to 29.9 ) & $1.97^{\mathrm{x}}$ & $1.70,2.27$ & $1.85^{\mathrm{x}}$ & $1.57,2.18$ \\
\hline Obese (30.0 or more) & $4.30^{\mathrm{x}}$ & $3.69,5.01$ & $4.08^{\mathrm{x}}$ & $3.45,4.83$ \\
\hline BMI (continuous) & $1.11^{\mathrm{x}}$ & $1.10,1.13$ & $1.11^{\mathrm{x}}$ & $1.09,1.13$ \\
\hline \multicolumn{5}{|l|}{ Pain and discomfort } \\
\hline Underweight $(<18.5)$ & 1.03 & $0.74,1.44$ & 1.14 & $0.80,1.63$ \\
\hline Normal weight (18.5 to 24.9 ; ref) & 1.00 & - & 1.00 & - \\
\hline Overweight (25.0 to 29.9 ) & 1.21 & $0.99,1.49$ & $1.34^{\dagger}$ & $1.08,1.66$ \\
\hline Obese ( 30.0 or more) & $1.31^{*}$ & $1.05,1.65$ & $1.38^{\dagger}$ & $1.09,1.74$ \\
\hline BMI (continuous) & $1.02^{\dagger}$ & $1.01,1.04$ & $1.02^{\dagger}$ & $1.01,1.04$ \\
\hline \multicolumn{5}{|l|}{ Stroke } \\
\hline Underweight $(<18.5)$ & $2.80^{\mathrm{x}}$ & $1.75,4.51$ & $3.08^{\mathrm{x}}$ & $1.83,5.17$ \\
\hline Normal weight (18.5 to 24.9 ; ref) & 1.00 & - & 1.00 & - \\
\hline Overweight (25.0 to 29.9 ) & 0.90 & $0.58,1.41$ & 1.07 & $0.67,1.71$ \\
\hline Obese (30.0 or more) & $1.76^{*}$ & $1.10,2.81$ & 1.48 & $0.90,2.41$ \\
\hline BMI (continuous) & $1.05^{*}$ & $1.00,1.09$ & $1.05^{*}$ & $1.00,1.09$ \\
\hline \multicolumn{5}{|l|}{ Urinary incontinence } \\
\hline Underweight $(<18.5)$ & $1.85^{\ddagger}$ & $1.31,2.61$ & $1.88^{\ddagger}$ & $1.29,2.73$ \\
\hline Normal weight ( 18.5 to 24.9 ; ref) & 1.00 & - & 1.00 & - \\
\hline Overweight (25.0 to 29.9 ) & 1.05 & $0.83,1.33$ & 0.95 & $0.73,1.25$ \\
\hline Obese ( 30.0 or more) & $1.74^{\mathrm{x}}$ & $1.34,2.26$ & $1.54^{\dagger}$ & $1.17,2.02$ \\
\hline BMI (continuous) & $1.03^{\mathrm{x}}$ & $1.02,1.05$ & $1.03^{\mathrm{x}}$ & $1.02,1.05$ \\
\hline
\end{tabular}

Data source: 2007-2008 Canadian Community Health Survey, Statistics Canada.

Abbreviations: BMI: body mass index; CI: confidence intervals; OR: odds ratio; $P$ : statistical significance; ref: reference; —: suppressed due to disclosure rules or not applicable.

${ }^{a}$ Models control for age (continuous) and sex.

${ }^{*} P<0.05 ;{ }^{\dagger} P \leq 0.01 ;{ }^{\ddagger} P \leq 0.001 ;{ }^{\mathrm{x}} P \leq 0.0001$.

the relationships were less striking upon correction in that the AORs weakened. These results were expected given the hypothesis and compelling argument made by Chiolero et al. [9] that the associations between obesity and health conditions may be overestimated if self-reported BMI is used. In their comparisons of AORs based on self-reported BMI with those based on measured BMI, researchers documented similar trends for diabetes, high blood pressure [10, 11], arthritis, and heart disease [10] in the past. The only other study that we are aware of to test Chiolero et al. hypothesis with corrected BMI data was conducted by Connor Gorber and colleagues [8], who focused on a smaller set of health conditions (i.e., diabetes, high blood pressure, heart disease, arthritis, activity limitation, and fair/poor self-perceived health), using Canadian national data. The work of Connor
Gorber et al. was also different from the current study because four separate correction models were evaluated against the results based on measured data, and the obese category was subdivided into two classes. With these differences aside, the main outcome of the regression analyses performed by Connor Gorber et al. parallels the reduced AORs observed in several circumstances on correction in the present study. Also, in unison with the current study, a few exceptions were noted by Connor Gorber and colleagues. For example, in the previous study, corrected values inflated relationships of excess body weight with arthritis among adults who were overweight or obese (classes II and III; BMI $\geq 35 \mathrm{~kg} / \mathrm{m}^{2}$ ). While this observation was not borne out in the present regression analyses, an exception to the reduction in the corrected AORs was found for pain and discomfort, namely 
the corrected AOR among overweight adults increased from the estimate based on self-reported BMI, and it gained significance.

Further support for the hypothesis put forth by Chiolero et al. [9] was found in the current analyses. Of particular note, unequivocal support for the hypothesis was provided by the fact that correction eliminated the significant relations between obesity and two chronic conditions (i.e., chronic bronchitis and stroke). Unlike our results, statistical significance was lost for diabetes with correction in one of Connor Gorber et al's [8] regression models, but no other direct comparisons can be made between the two studies, as the health conditions under study were not identical.

Turning our attention to the literature comparing selfreported with measured BMI data, in a study with 961 Mexican adults [23], a positive association between obesity and asthma was only apparent for women on self-report, but was evident for both sexes with physical measurements. These findings run counter to the results for asthma obtained in our research. On the other hand, in two other studies with measured BMI data, comparable patterns for diabetes emerged, such as the one observed in the present study [10, 11]. In fact, in one of the studies [10], the seemingly significant relationship between being overweight and diabetes was eliminated with the use of height and weight measurements.

Despite the fact that previous researchers have repeatedly concluded that obesity is associated with cancer [3], this study did not provide further evidence for this conclusion. Cancer was not significantly associated with obesity or increasing body weight in our data analysis. The subdivision of the obese category into different classes of obesity would have fleshed out a more detailed analysis, and it may have generated different results. In addition, perhaps a cancerspecific analysis would have produced different results since obesity is only associated with certain malignancies in prior research [3]. Moreover, all of the results of this study should be interpreted with some caution. As this study had a crosssectional design, causal inferences cannot be made. Also, we acknowledge that reciprocal and complex relationships exist between obesity and chronic diseases, such as CVD [24]. Furthermore, as described in more detail elsewhere [17], there were other limitations to the present research. The limitations included the $45 \%-60 \%$ provincial response rates for the MHW subsample, the small subsample size, the absence of intra- and interrater reliability testing to exclude significant BMI measurement error, the limitations of the BMI itself as an mechanism to measure body fat, and the reduced sensitivity values for the normal weight population with the correction method used in this study.

\section{Conclusions}

Chiolero et al. [9] pointed out that using self-reported BMI data exaggerates obesity-chronic disease relations. Our research supported this hypothesis, although in many cases the relationships remained significant even though the AORs were reduced. Although these findings do not diminish the importance of public health messaging to encourage healthy weights, they do indicate that more research is needed to fully understand how the usage of self-reported data alters our understanding of the relationships between overweight or obesity and chronic diseases.

\section{Conflict of Interests}

The authors declare no conflict of interests.

\section{References}

[1] World Health Organization. Obesity and overweight, c2012, http://www.who.int/mediacentre/factsheets/fs311/en/index .html.

[2] World Health Organization. Controlling the global obesity epidemic. c2012, http://www.who.int/nutrition/topics/obesity/ en/.

[3] D. P. Guh, W. Zhang, N. Bansback, Z. Amarsi, C. L. Birmingham, and A. H. Anis, "The incidence of co-morbidities related to obesity and overweight: a systematic review and meta-analysis," BMC Public Health, vol. 9, article 88, 2009.

[4] H. Jia and E. I. Lubetkin, "Trends in quality-adjusted life-years lost contributed by smoking and obesity," American Journal of Preventive Medicine, vol. 38, no. 2, pp. 138-144, 2010.

[5] H. M. Orpana, J. M. Berthelot, M. S. Kaplan, D. H. Feeny, B. McFarland, and N. A. Ross, "BMI and mortality: results from a national longitudinal study of Canadian adults," Obesity, vol. 18, no. 1, pp. 214-218, 2010.

[6] A. H. Anis, W. Zhang, N. Bansback, D. P. Guh, Z. Amarsi, and C. L. Birmingham, "Obesity and overweight in Canada: an updated cost-of-illness study," Obesity Reviews, vol. 11, no. 1, pp. 31-40, 2010.

[7] Public Health Agency of Canada and the Canadian Institute for Health Information. Obesity in Canada, The Agency and Institute, Ottawa, Canada, 2011.

[8] S. Connor Gorber, M. Shields, M. S. Tremblay, and I. McDowell, "The feasibility of establishing correction factors to adjust selfreported estimates of obesity," Health Reports, vol. 19, no. 3, pp. 71-82, 2008.

[9] A. Chiolero, I. Peytremann-Bridevaux, and F. Paccaud, "Associations between obesity and health conditions may be overestimated if self-reported body mass index is used," Obesity Reviews, vol. 8, no. 4, pp. 373-374, 2007.

[10] M. Shields, S. Connor Gorber, and M. S. Tremblay, "Effects of measurement on obesity and morbidity," Health Reports, vol. 19, no. 2, pp. 77-84, 2008.

[11] M. Yannakoulia, D. B. Panagiotakos, C. Pitsavos, and C. Stefanadis, "Correlates of BMI misreporting among apparently healthy individuals: the ATTICA study," Obesity, vol. 14, no. 5, pp. 894-901, 2006.

[12] M. Shields, S. Connor Gorber, and M. S. Tremblay, "Estimates of obesity based on self-report versus direct measures," Health Reports, vol. 19, no. 2, pp. 61-76, 2008.

[13] M. Shields, S. Connor Gorber, I. Janssen, and M. S. Tremblay, "Bias in self-reported estimates of obesity in Canadian health surveys: an update on correction equations for adults," Health Reports, vol. 22, no. 3, pp. 1-11, 2011.

[14] Statistics Canada. Canadian Community Health Survey (CCHS): 2007 Microdata files user guide. c2008, http:// www.statcan.gc.ca/imdb-bmdi/document/3226_D7_T9_V4eng.pdf. 
[15] Statistics Canada. Canadian Community Health Survey (CCHS)-Annual component: User guide 2008 microdata files. c2009, http://www.statcan.gc.ca/imdb-bmdi/document/ 3226_D7_T9_V5-eng.pdf.

[16] Health Canada. Canadian guidelines for body weight classification in adults: Quick reference tool for professionals. c2008, http://www.hc-sc.gc.ca/fn-an/nutrition/weights-poids/guideld-adult/cg_quick_ref-ldc_rapide_ref-eng.php.

[17] C. L. Murray, G. W. Walsh, and S. Connor Gorber, "A comparison between Atlantic Canadian and National correction equations to improve the accuracy of self-reported obesity estimates in Atlantic Canada," Journal of Obesity, vol. 2012, Article ID 492410, 7 pages, 2012.

[18] M. Lalonde, A New Perspective on the Health of Canadians, Minister of Supply and Services, Ottawa, Canada, 1974.

[19] US Surgeon General, Healthy People: The Surgeon General's Report on Health Promotion and Disease Prevention, US Department of Health, Education and Welfare/Public Health Service, Washington, DC, USA, 1979.

[20] K. Hayward and R. Colman, Population and Public Health Branch, Atlantic Regional Office, Health Canada. The Tides of Change: Addressing Inequity and Chronic Disease in Atlantic Canada, Health Canada, Halifax, Canada, 2003.

[21] Public Health Agency of Canada, Tracking Heart Disease and Stroke in Canada, Public Health Agency of Canada, Ottawa, Canada, 2009.

[22] D. Yach and R. Beaglehole, "Globalization of risks for chronic diseases demands global solutions," Perspectives on Global Development and Technology, vol. 3, no. 1-2, pp. 213-233, 2004.

[23] A. A. Santillan and C. A. Camargo, "Body mass index and asthma among Mexican adults: the effect of using self-reported vs measured weight and height," International Journal of Obesity, vol. 27, no. 11, pp. 1430-1433, 2003.

[24] P. M. Dubbert, T. Carithers, A. E. Sumner et al., "Obesity, physical inactivity, and risk for cardiovascular disease," American Journal of the Medical Sciences, vol. 324, no. 3, pp. 116-126, 2002. 


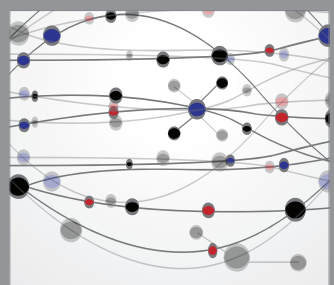

The Scientific World Journal
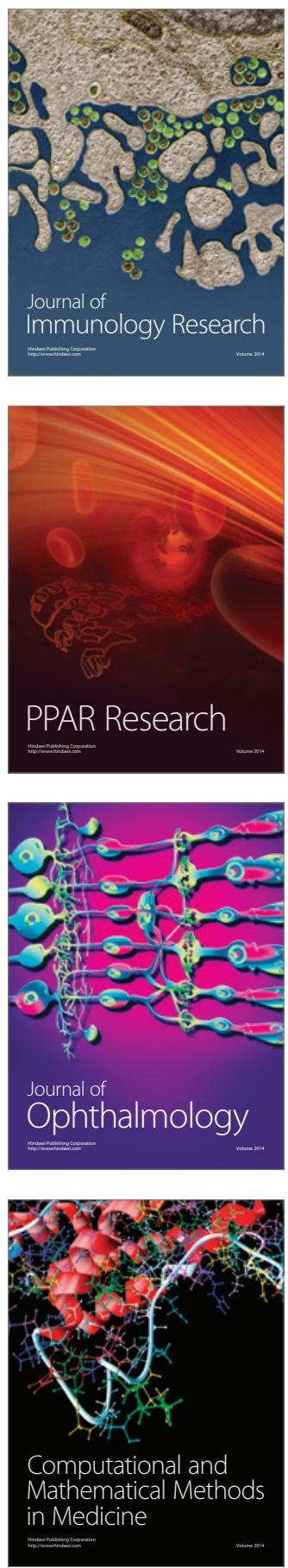

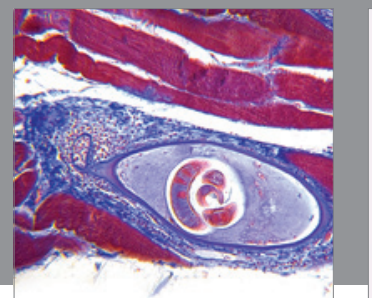

Gastroenterology

Research and Practice
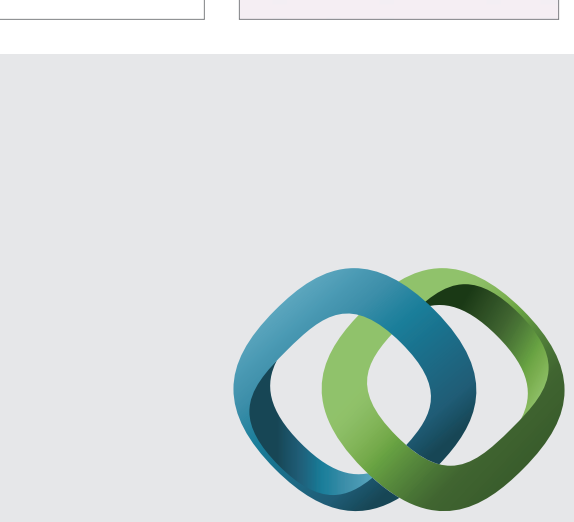

\section{Hindawi}

Submit your manuscripts at

http://www.hindawi.com
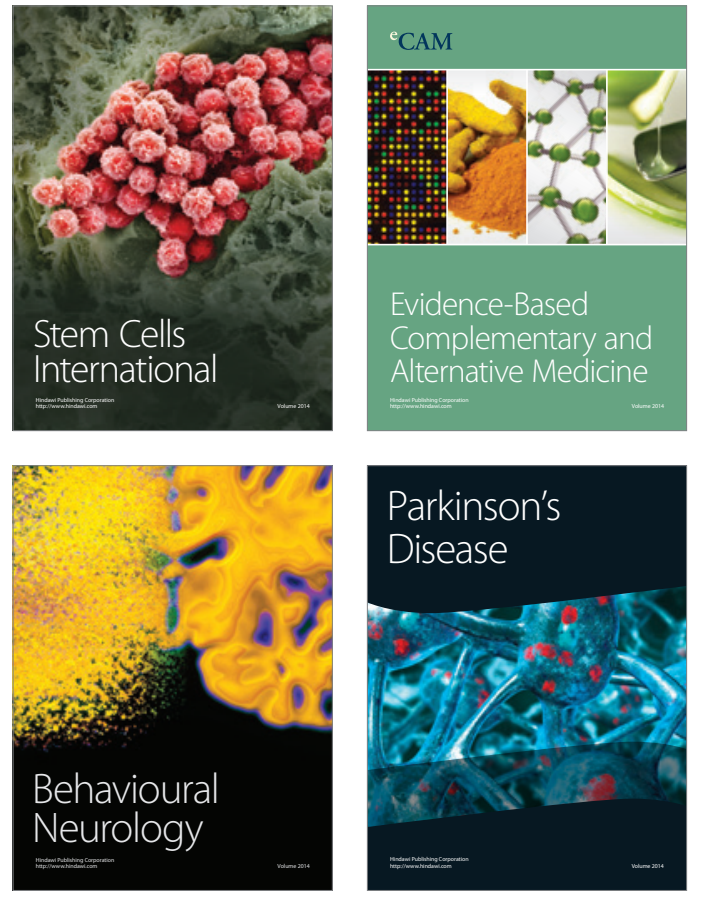
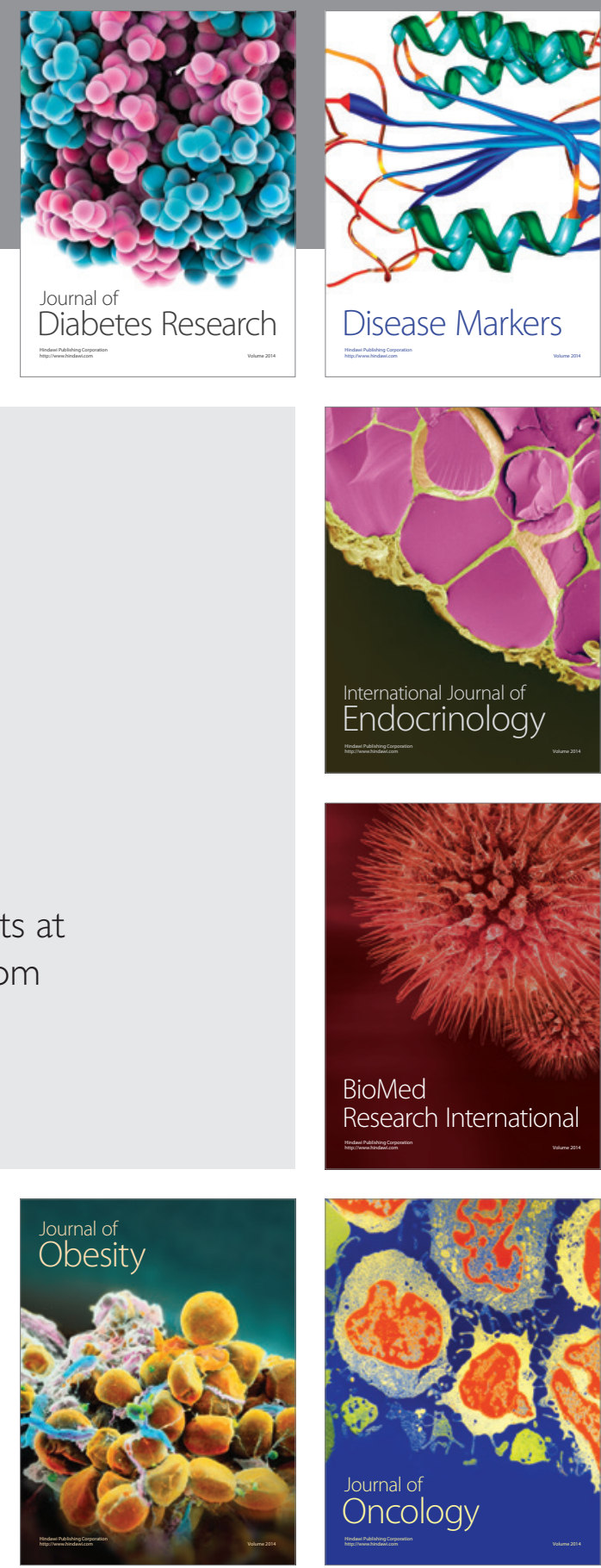

Disease Markers
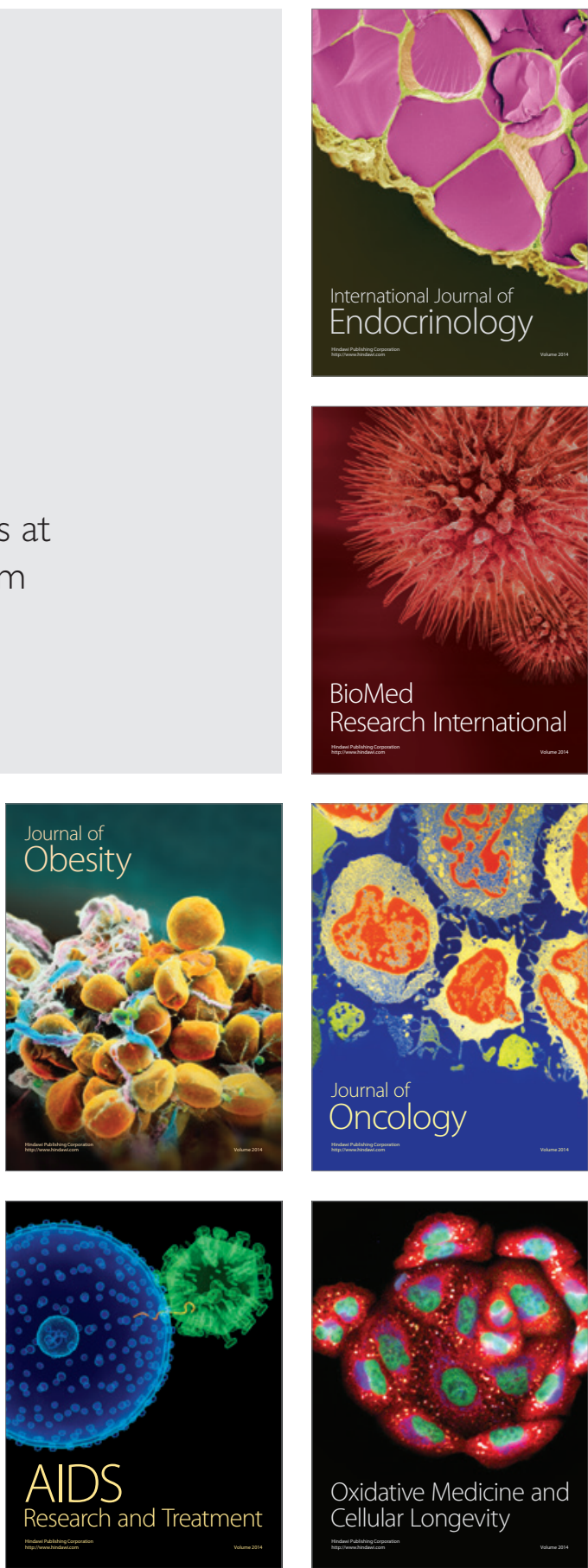